Integração entre Internet e Prática Docente de Química

\author{
Rolando, L. G. R.; Vasconcellos, R. F. R. R.; Moreno, E. L.; Salvador, D. F.; \\ Luz, M. R. M. P.
}

Rev. Virtual Quim., 2015, 7 (3), 864-879. Data de publicação na Web: 30 de dezembro de 2014

http://www.uff.br/rvq

\title{
Integration between Internet and Chemistry Teaching Practice
}

\begin{abstract}
The study aimed to identify the main characteristics of the internet use by secondary chemistry teachers of the State of Rio de Janeiro. Most teachers recognize and use the internet for learning. This usage is focused mainly for searching information on chemical content for individual use. Although public policies will encourage the use of such tools in educational contexts, the didactic use of internet tools remains distant from the classrooms of Chemistry. We discussed the importance of articulating policies and teacher training programs through the development of outreach activities about the pedagogical potential of the internet tools among teachers.
\end{abstract}

Keywords: Chemistry teaching; in-service teachers; internet.

\section{Resumo}

O estudo teve como objetivo identificar as principais características do uso da internet por professores de Química do ensino médio do Estado do Rio de Janeiro. A maioria dos professores reconhece e usa a internet para aprender, principalmente por meio de busca de informações sobre conteúdo químico para uso individual. Embora políticas públicas incentivem o uso didático de ferramentas da internet em contextos educacionais, o uso de tais ferramentas permanece distante das salas de aula de Química. Discutimos a importância de articular políticas e programas de formação de professores que proporcionem atividades de sensibilização sobre o potencial pedagógico das ferramentas de internet entre os professores.

Palavras-chave: Ensino de química; formação continuada de professores; internet.

\footnotetext{
* Instituto Oswaldo Cruz, Laboratório de Avaliação em Ensino e Filosofia das Biociências, Av. Brasil, 4365, Manguinhos, CEP 21040-360, Rio de Janeiro-RJ, Brasil.

Mgustavor@ioc.fiocruz.br

DOI: $10.5935 / 1984-6835.20150044$
} 


\section{Integração entre Internet e Prática Docente de Química}

\section{Luiz Gustavo R. Rolando, ${ }^{a}$ Roberta Flávia R. R. Vasconcellos, ${ }^{\text {b,c }}$ Esteban L. Moreno, ${ }^{\mathrm{b}}$ Daniel Fábio Salvador, ${ }^{\mathrm{b}}$ Maurício Roberto M. P. da Luz ${ }^{\mathrm{a}}$}

a Instituto Oswaldo Cruz, Laboratório de Avaliação em Ensino e Filosofia das Biociências, Av. Brasil, 4365, Manguinhos, CEP 21040-360, Rio de Janeiro-RJ, Brasil.

${ }^{b}$ Fundação Centro de Ciências e Educação Superior a Distância, Rua da Ajuda, n 5, 16 andar, Centro, CEP 20040-000, Rio de Janeiro-RJ, Brasil.

c Universidade do Grande Rio, Rua Prof. José de Souza Herdy, 1.160, 25 de Agosto, CEP 25071202, Duque de Caxias-RJ, Brasil.

* gustavor@ioc.fiocruz.br

\section{Introdução}

\section{Metodologia}

2.1. Contexto do estudo

2.2. Instrumento de coleta de dados

2.3. Análise dos dados

\section{Resultados}

\section{Discussão}

4.1. Formação inicial e continuada

4.2. Políticas institucionais

4.3. O fator sociocultural

\section{Conclusões}

\section{Introdução}

A escolha de boas práticas no uso das tecnologias de informação e comunicação (TICS) é uma importante necessidade, constituindo uma linguagem de comunicação essencial na sociedade contemporânea. ${ }^{1}$ As relações sociais têm sido influenciadas pela informatização e pelo paradigma tecnológico, caracterizado pela alta velocidade em que a informação é gerada, processada e compartilhada. ${ }^{2}$ Nesse panorama, as TICs passaram a possibilitar a utilização de novos processos de ensino e aprendizagem em rede, baseados na interação e na criação coletiva. ${ }^{3}$ Mais recentemente, com a popularização da internet e o acelerado avanço tecnológico, surgem a todo o momento mais tecnologias digitais e inúmeras tentativas de utilizá-las para fins educacionais. ${ }^{4}$ 
A evolução da internet conhecida como Web 1.0 (distributiva) para a Web 2.0 (colaborativa) ampliou suas possibilidades pedagógicas. A Web 1.0 é caracterizada pela divisão de papéis entre produtores e usuários finais (consumidores) de informação, pela produção centralizada de conteúdos, sites estáticos e principalmente pela distribuição unidirecional do conhecimento por meio de mecanismos de download..$^{5} \mathrm{O}$ conceito de Web 2.0 define um novo tipo de experiência de uso da internet, a Web como plataforma na qual o uso de ferramentas com maior potencial de interatividade cria um efeito de rede por meio da participação e colaboração entre os usuários. ${ }^{5}$

Instituições internacionais, como a British Educational Communications and Technology Agency, ${ }^{6}$ American Association for the Advancement of Science ${ }^{7}$ e a Organização das Nações Unidas para a Educação a Ciência e a Cultura $^{8,9,10}$, têm recomendado e promovido o uso das TICs no ensino e aprendizagem. A exemplo do cenário mundial, documentos oficiais brasileiros também reforçam a importância da utilização das TICs na educação. A resolução CNE/CP no 1/2002 do Conselho Nacional de Educação sugere que a formação para a atividade docente deve contemplar o uso de tecnologias da informação e da comunicação ${ }^{11}$ e, mais recentemente, a Conferência Nacional de Educação enfatizou a importância das TICs no contexto educacional, bem como da efetivação de uma política de formação de professores para o seu uso. ${ }^{12}$ Influenciado por esse movimento global em favor da tecnologia, o governo brasileiro tem investido recursos para equipar as escolas com computadores e ferramentas de comunicação. ${ }^{13}$ Além disso, algumas ações em parceria com as instituições superiores de ensino têm sido realizadas visando à melhoria do uso de tecnologias na educação básica do país. ${ }^{14}$

Estudos têm relatado o impacto do uso das TICs na educação básica, buscando compreender como estudantes e professores estão lidando com essas ferramentas. ${ }^{15,16,17}$ Os resultados dessas pesquisas mostram que, apesar do aumento no uso de TICs na educação, os professores raramente usam essas ferramentas de forma a impactar positivamente seus contextos educacionais. ${ }^{17,18,19} \mathrm{O}$ uso das TICs nas escolas é influenciado por muitos fatores, como o conhecimento dos professores acerca das TICS, bem como a habilidade no uso dessas ferramentas, os currículos nacionais e a infraestrutura das escolas. ${ }^{17}$

Essas novas tecnologias podem ser utilizadas para apoiar e favorecer a aprendizagem, criar situações baseadas em problemas do mundo real na sala de aula, dar oportunidades de feedback e reflexão, construir comunidades de aprendizagem, além de expandir as possibilidades de aprendizado para o professor. ${ }^{20}$ Dessa forma, a utilização de recursos disponíveis na internet, além de permitir ao professor da educação básica se manter atualizado frente às demandas da nova sociedade inserida na era do conhecimento, poderá também aproximá-lo de seus alunos, adolescentes e jovens, que são nativos digitais, usuários frequentes e intensivos da internet. ${ }^{21,22}$

Segundo Osborne e Hennessy, ${ }^{23}$ o uso de TICs nas aulas de ciências naturais (Química, Física e Biologia) no contexto da educação básica, traz diversos benefícios aos estudantes, tais como desenvolvimento da habilidade de pensamento crítico, de manipulação e coleta de dados, bem como o aumento do acesso ao conhecimento apresentado em formato visual, da motivação e do engajamento. Adicionalmente, no ensino aprendizagem de Ciências o entendimento e visualização dos fenômenos naturais poderiam ser beneficiados pelo uso de recursos baseados na conjunção de texto, imagem e som, disponíveis em vídeos, animações, simulações, entre outros. Apesar disto, relatos indicam que a utilização das TICS pelos professores ainda está frequentemente limitada à preparação de textos para as aulas e para a comunicação pessoal por e-mail, e não para o ensino de ciências, para qual a pesquisa sugere mais benefícios para a aprendizagem. ${ }^{18,24}$ Uma ampla revisão de 
literatura, sobre a aprendizagem de Ciências baseada na internet, indica que as atividades de busca de informação online podem promover a aprendizagem autorregulada. ${ }^{25}$ Além disso, o uso de ambientes virtuais favorece a habilidade de argumentação científica, de interpretação e de processamento de dados, gerando melhorias em relação às atitudes e motivação dos estudantes. $^{25}$

No Brasil, uma pesquisa realizada com alunos do $7^{\circ}$ ano da educação básica na qual foram utilizadas algumas TICs (projeção de imagens em PowerPoint, visualização de vídeos educativos e busca na internet) identificou melhoria no desempenho dos alunos, com um aumento de $10 \%$ na média da turma na disciplina de Ciências. ${ }^{26}$ Cerca de 92\% dos alunos tiveram sua aprendizagem influenciada positivamente pelas TICs, o que, segundo os autores, teve como razões principais a melhoria da atenção e o aumento do entusiasmo de aprender. ${ }^{26}$

Recentemente, grandes universidades nos Estados Unidos (MIT, Stanford, Harvard) e no Brasil (USP, UFF, dentre outras) têm disponibilizado abertamente na internet o conteúdo de alguns cursos. No contexto da Química, um bom exemplo é o Portal do Conhecimento da Sociedade Brasileira de Química (QNInt). ${ }^{27}$ Segundo os autores, o QNInt é um recurso estabelecido e bem sucedido de divulgação do conhecimento químico. Essa parece ser uma tendência a ser desenvolvida pelos grandes centros produtores de conhecimento. Neste mesmo âmbito, é necessário citar outras iniciativas importantes em língua portuguesa, como os Conteúdos Digitais Educacionais de Química (http://condigital.cursosccead.net/condigital) do CCEAD da PUC-Rio, o Almanaque Sonoro de

Química

(http://www.almanaquesonoro.com/quimica ) da mesma instituição, o Ponto Ciência (http://www.pontociencia.org.br) organizado pela UFMG e a Química das Coisas (www.aquimicadascoisas.org) da Universidade de Aveiro em Portugal. Outros repositórios de objetos educacionais multimídia na área de Ciências têm sido criados a fim congregar no universo digital esses recursos, seja em formato de texto, vídeo, áudio, imagem e animação. Entre eles, destaca-se o Banco Internacional de Objetos Educacionais, do Ministério de Educação do Brasil

(http://objetoseducacionais2.mec.gov.br).

A incorporação da internet no ensino de Ciências evidentemente precisa ocorrer em um contexto que favoreça a aprendizagem e o desenvolvimento de habilidades e competências intrínsecas. A incorporação de ferramentas da internet poderia impactar positivamente $\mathrm{o}$ ensino aprendizagem de Ciências, especialmente da Química, de professores em exercício e alunos da educação básica.

A escassez de estudos sobre o uso da internet por professores brasileiros, especialmente professores de química, faz com que seja necessário identificar e caracterizar essa utilização, a fim de oferecer apoio às diversas iniciativas de formação de professores já em curso no país que visam impactar positivamente o ensino de Ciências. Dessa forma, o presente estudo teve como objetivo identificar o perfil de uso da internet e suas ferramentas por professores de Química do ensino médio do Estado do Rio de Janeiro, bem como caracterizar o propósito de utilização dessas ferramentas. A relevância geral dos resultados para o ensino de Ciências na educação básica também é discutida.

\section{Metodologia}

\subsection{Contexto do estudo}

A Fundação Centro de Ciências e Educação Superior a Distância do Estado do Rio de Janeiro (Fundação CECIERJ http://www.cederj.edu.br) tem oferecido, há mais de uma década, cursos gratuitos de extensão para a formação continuada de 
professores. Os cursos são realizados com o apoio das tecnologias de informação e comunicação (TICS), oferecidos via internet, por meio da plataforma Moodle (Modular Object-Oriented Dynamic Learning Environment). Cada curso tem uma carga de trabalho estimada de 30 horas, distribuídas por um período de quatro meses. Os participantes da pesquisa são 186 professores de Química do ensino médio do Estado do Rio de Janeiro matriculados nos cursos de extensão em Química da Fundação CECIERJ no ano de 2012.

\subsection{Instrumento de coleta de dados}

Para fins de coleta dos dados analisados na presente pesquisa foi utilizado um questionário on line composto de 18 questões, denominado Questionário de Uso da Internet - QUI (ANEXO 1). Esse instrumento foi validado em estudo prévio com professores de Biologia. ${ }^{28} \mathrm{O}$ questionário foi aplicado na primeira semana dos cursos, com o objetivo de caracterizar a frequência de uso da internet, as ferramentas utilizadas e as finalidades dessa utilização. Existe uma ampla variedade de ferramentas disponíveis na Web que não seria exequível construir um instrumento de pesquisa incluindo todas eles. Algumas ferramentas, tais como o e-mail podem ser utilizadas a partir de diferentes serviços ou sites (provedores de webmail, por exemplo). Outras ferramentas, com fins de compartilhamento de recursos, como por exemplo o Dropbox, podem ser vistas como ações (upload e download). Portanto, o termo ferramenta deve ser visto como uma forma de incluirmos diferentes nomenclaturas, na análise do uso da internet, já que inclui marcas (por exemplo, Facebook), ações (por exemplo, download) e serviços (por exemplo, e-mail). Nós decidimos utilizar o termo ferramenta, uma vez que tem sido largamente utilizado na literatura internacional. ${ }^{28}$

O conjunto de ferramentas da internet analisados por meio do QUI possui uma diferenciação em relação à complexidade de utilização das ferramentas mais comuns e simples, até aquelas que exigem um domínio maior da internet pelo usuário, elas podem representar também o uso da internet sobre a perspectiva do entendimento de rede distributiva (Web 1.0) ou rede colaborativa (Web 2.0). O questionário é composto de perguntas fechadas, a maioria delas com resposta afirmativa ou negativa, seguida de questão aberta sobre a finalidade de uso de tal ferramenta (ANEXO 1).

\subsection{Análise dos dados}

Para fins de análise das respostas abertas dos questionários utilizamos metodologia qualitativa para encontrar características comuns seguindo procedimento de análise de conteúdo, em que os dados são identificados, nomeados e codificados. ${ }^{29} \mathrm{O}$ trabalho de análise utilizou categorias analíticas baseadas nas finalidades de uso da internet obtidas por Rolando, Salvador e Luz. ${ }^{28}$ A partir da recorrência de características comuns, os temas e tipos de enunciados identificados nas respostas foram agrupados nas respectivas categorias, como demonstrado no Quadro 1. Uma única resposta pôde contribuir para uma, duas ou mais categorias, já que os professores relataram um, dois ou mais propósitos de utilização para cada uma das ferramentas investigadas. 
Quadro 1. Categorias e finalidades de uso das ferramentas da internet

\begin{tabular}{|c|c|c|}
\hline Categoria & Definição (Uso) & Exemplos \\
\hline Estudo & $\begin{array}{l}\text { Estudar e aprender temas } \\
\text { referentes à área de } \\
\quad \text { formação. }\end{array}$ & $\begin{array}{c}\text { "Faço pesquisa na internet sobre conteúdos de } \\
\text { Química." } \\
\text { "Participo de fóruns para enriquecimento de } \\
\text { conhecimento e saber outros pontos de vista sobre um } \\
\text { determinado tema." }\end{array}$ \\
\hline Didático & $\begin{array}{l}\text { Relacionados com a prática } \\
\text { docente, tais como } \\
\text { preparar e dar aula. }\end{array}$ & $\begin{array}{c}\text { "Realizo pesquisa na internet sobre atividades, } \\
\text { exercícios e provas de química para preparar minhas } \\
\text { aulas." } \\
\text { "Eu baixo vídeo aulas ou assuntos que possam ser } \\
\text { dados em sala de vídeo e sala de aula com o data } \\
\text { show." }\end{array}$ \\
\hline Profissional & $\begin{array}{l}\text { Referente à prática } \\
\text { profissional, desde que não } \\
\text { relacionado aos propósitos } \\
\text { definidos como Estudo e } \\
\text { Didático. }\end{array}$ & $\begin{array}{c}\text { "Utilizo o Twitter para divulgar meu trabalho de } \\
\text { professor particular online." } \\
\text { "Uso fórum para saber notícias pertinentes aos } \\
\text { servidores do Estado." }\end{array}$ \\
\hline Social & $\begin{array}{l}\text { Comunicação pessoal com } \\
\text { amigos e parentes. }\end{array}$ & $\begin{array}{l}\text { "Uso o chat para me comunicar com amigose } \\
\text { parentes distantes." } \\
\text { "Uso o Facebook para manter contato com amigos e } \\
\text { familiares." }\end{array}$ \\
\hline Outros & $\begin{array}{l}\text { Propósitos que não podem } \\
\text { ser enquadrados nas } \\
\text { categorias acima. }\end{array}$ & $\begin{array}{c}\text { "Uso o Facebook para participar de promoções e } \\
\text { entretenimento." }\end{array}$ \\
\hline
\end{tabular}

\section{Resultados}

A maior parte dos professores analisados nesta pesquisa declarou-se usuário frequente da internet. De acordo com as respostas obtidas por meio do Questionário de Uso da Internet (QUI), 79,6\% deles acessam a internet entre 6 e 7 dias por semana, $17,7 \%$ acessam 3 a 5 dias por semana e apenas 2,7\% declararam acessar raramente a dois dias por semana. $O$ acesso à internet no Brasil vem aumentando ano a ano ao longo da última década, chegando a 77,8 milhões de internautas com 16 anos ou mais ao final de $2011 .^{30}$ Dados de 2012 revelam que $92 \%$ dos professores que lecionam em escolas públicas e $95 \%$ dos que lecionam em escolas particulares possuem acesso à internet no domicílio. ${ }^{31}$ A partir desses dados podemos perceber que professores, de forma geral, possuem acesso e fazem uso frequente da internet.

As ferramentas da internet utilizadas pelos professores são apresentadas na figura 1. Todos os professores usam e-mail, $99 \%$ deles fazem pesquisa na internet por meio de motores de busca e $95 \%$ realizam download. Esses resultados demonstram que a grande maioria dos professores utiliza a internet para obter informação e se comunicar. Os resultados são corroborados por outros estudos que têm identificado este mesmo padrão de uso predominante de sites de busca, editores de texto e e-mail por professores, tanto no Brasi $^{32,33}$ como em outros países, ${ }^{18,24,34}$ indicando que os professores reconhecem a internet como 
Rolando, L. G. R. et al.

fonte de informações.

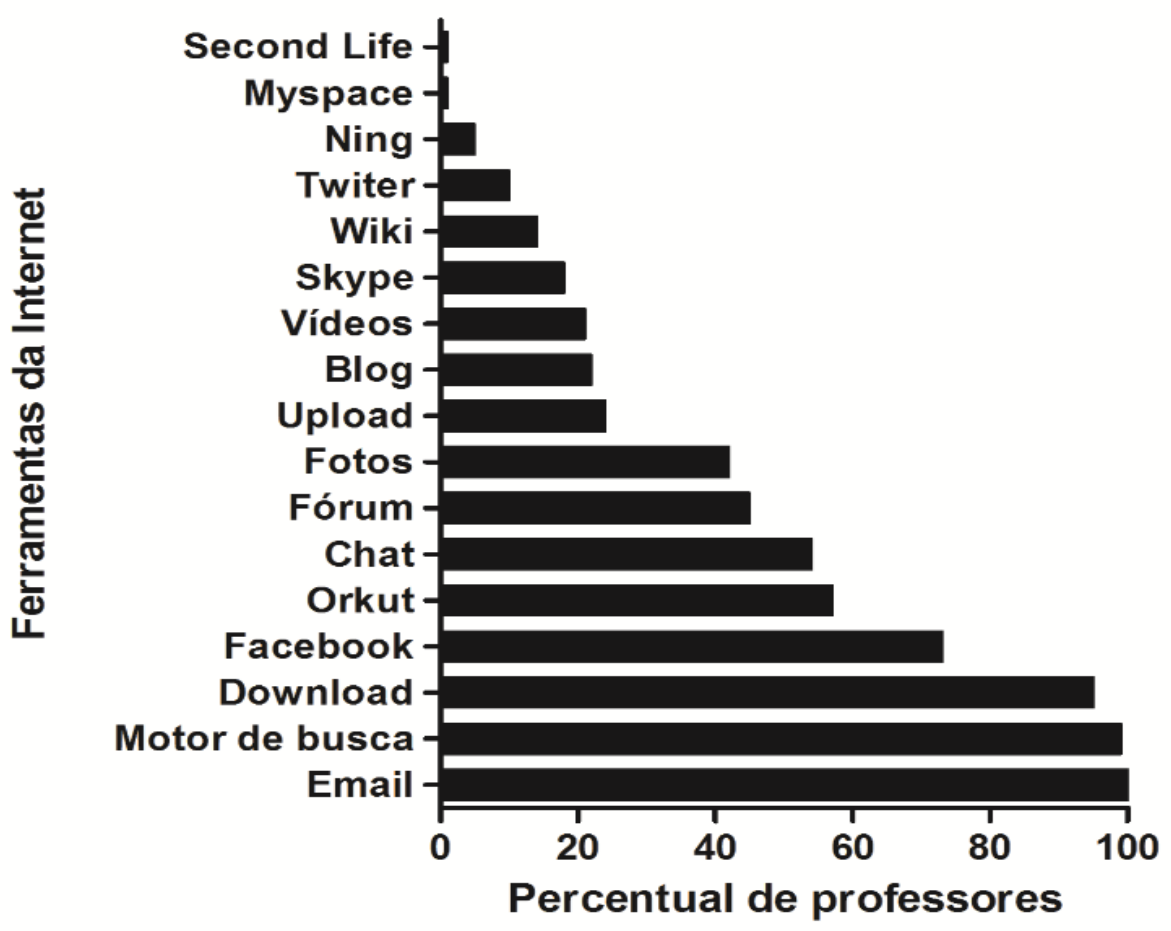

Figura 1. Utilização das ferramentas da internet por professores de Química $(n=186)$

Seguindo a tendência atual de utilização de redes sociais pela população em geral, ${ }^{35}$ $73 \%$ dos professores se declararam usuários do Facebook e $57 \%$ do Orkut (Figura 1), sugerindo que além de utilizarem as ferramentas mais tradicionais (exemplo: email), eles possuem interesse por ferramentas mais recentes, que proporcionam uma maior interatividade com outras pessoas por meio da internet. Em estudo prévio, realizado com professores de Biologia no ano de 2010, a rede social Orkut era a mais utilizada pelos professores, enquanto o Facebook era utilizado por uma pequena parte deles. ${ }^{28}$ Nestes últimos anos, o Facebook superou as demais redes sociais se tornando a mais utilizada no Brasil, ${ }^{36}$ o que reforça a característica de constante mudança de utilização das ferramentas disponíveis na internet. ${ }^{4}$ Outras ferramentas que funcionam como redes sociais, Second Life, Myspace, Ning e Twitter, são pouco utilizadas pelos professores, o que pode estar relacionado com a necessidade de maior conhecimento sobre as especificidades de cada uma delas. No caso do Second Life, o problema é agravado pela necessidade de uma maior estrutura de hardware e banda de internet, o que ainda não é amplamente disponível entre os brasileiros.

Além de identificar quais ferramentas da internet são mais utilizadas pelos professores, o instrumento de coleta de dados nos permitiu caracterizar os propósitos pelos quais essas ferramentas são utilizadas, configurando um perfil geral de uso da internet por professores de Química. Para entender essas finalidades, determinamos as porcentagens de respostas abertas incluídas em cada uma das cinco categorias. Os professores, em alguns casos, relataram a utilização de uma única ferramenta para duas ou mais finalidades e, como resultado, o número de usos excedeu o número total de professores. Os resultados dessa categorização estão mostrados na tabela 1.

Um conjunto de sete ferramentas 
(Motores de busca, E-mail, Chat, Fórum, Skype , Vídeo e Blog) demonstrou ser mais versátil que as demais, sendo utilizadas para todas as finalidades apresentadas, ainda que alguns usos específicos predominem sobre os demais. De modo geral, os variados tipos de ferramentas de comunicação são utilizados preponderantemente para a finalidade de se comunicar com amigos e parentes (categoria Social). Por exemplo, $79,9 \%$ do uso da rede social Facebook e $46,3 \%$ do uso da ferramenta Skype é realizado para fins de socialização. Em outros casos, as ferramentas são usadas quase exclusivamente para uma finalidade, por exemplo, Wiki $(88,9 \%)$ e Ning (100\%) que, embora sejam relativamente pouco utilizados, estão associados com a finalidade de estudo (Tabela 1).

Seis das ferramentas da internet selecionadas foram usadas principalmente para fins de socialização, enquanto outras cinco delas para fins de estudo, mas nenhuma foi usada preponderantemente para fins didáticos ou de gestão profissional (categoria Profissional). Embora a categoria "Outros" apresente maior percentual de uso para seis das ferramentas analisadas, não foi possível encontrar padrões de semelhança nos propósitos relatados pelos professores ao utilizarem essas ferramentas. Essa categoria apresenta características extremamente variadas, pois para cada uma das ferramentas existem inúmeros motivos de utilização que não se enquadram nas categorias anteriores. Além disso, há finalidades que ocorrem apenas para uma ferramenta, como, por exemplo, no caso de Download, é comum o relato da obtenção de filmes, músicas e programas de computador. Já na categoria Profissional, procuramos separar a utilização das ferramentas para fins que não configurassem $o$ processo de estudar e aprender do professor e também não indicasse a utilização para fins didáticos, mas que de alguma forma estivesse relacionado ao seu trabalho. Observamos que os professores fazem pouco uso das ferramentas da internet para a finalidade Profissional (Tabela 1). Esse uso se limita principalmente a E-mail e Blog, ferramentas que possibilitam a comunicação e divulgação profissional.

Tabela 1. Motivos de uso relatados pelos professores para cada ferramenta. a Finalidades $(n=1642)$ apresentadas pelos professores em suas respostas às questões abertas. $b$ Destaques em negrito para a principal finalidade de cada ferramenta

\begin{tabular}{ccccccc}
\hline & $\mathrm{n}^{\text {a }}$ & Estudo & Didático & Profissional & Social & Outros \\
\hline M. busca & 293 & $48,1 \%{ }^{\mathrm{b}}$ & $7,2 \%$ & $1,4 \%$ & $0,7 \%$ & $42,7 \%$ \\
E-mail & 300 & $15,3 \%$ & $1,0 \%$ & $23,7 \%$ & $34,7 \%$ & $25,3 \%$ \\
Chat & 129 & $10,1 \%$ & $3,9 \%$ & $5,4 \%$ & $45,7 \%$ & $34,9 \%$ \\
Fórum & 92 & $57,6 \%$ & $4,3 \%$ & $1,1 \%$ & $1,1 \%$ & $35,9 \%$ \\
Skype & 41 & $7,3 \%$ & $2,4 \%$ & $2,4 \%$ & $46,3 \%$ & $41,5 \%$ \\
Download & 238 & $35,3 \%$ & $3,4 \%$ & $0,0 \%$ & $0,0 \%$ & $61,3 \%$ \\
Upload & 48 & $22,9 \%$ & $4,2 \%$ & $0,0 \%$ & $0,0 \%$ & $72,9 \%$ \\
Foto & 88 & $2,3 \%$ & $0,0 \%$ & $0,0 \%$ & $72,7 \%$ & $25,0 \%$ \\
Vídeo & 47 & $25,5 \%$ & $19,1 \%$ & $4,3 \%$ & $17,0 \%$ & $34,0 \%$ \\
Blog & 46 & $34,8 \%$ & $15,2 \%$ & $10,9 \%$ & $8,7 \%$ & $30,4 \%$ \\
Twitter & 26 & $7,7 \%$ & $0,0 \%$ & $0,0 \%$ & $7,7 \%$ & $84,6 \%$ \\
Wiki & 27 & $88,9 \%$ & $0,0 \%$ & $3,7 \%$ & $0,0 \%$ & $7,4 \%$ \\
Orkut & 111 & $0,0 \%$ & $0,0 \%$ & $0,9 \%$ & $78,4 \%$ & $20,7 \%$ \\
Facebook & 143 & $2,1 \%$ & $0,0 \%$ & $1,4 \%$ & $79,7 \%$ & $16,8 \%$ \\
Myspace & 2 & $0,0 \%$ & $0,0 \%$ & $0,0 \%$ & $0,0 \%$ & $100,0 \%$ \\
Ning & 10 & $100,0 \%$ & $0,0 \%$ & $0,0 \%$ & $0,0 \%$ & $0,0 \%$ \\
Sec. Life & 1 & $0,0 \%$ & $0,0 \%$ & $0,0 \%$ & $0,0 \%$ & $100,0 \%$ \\
\hline
\end{tabular}


Do total de 1642 usos declarados pelos professores (Tabela 1), 420 (25,6\%) são referentes a fins de estudo (Categoria Estudo). Ao analisarmos esse propósito, podemos observar que os professores utilizam, principalmente, as ferramentas Motores de busca e Download para estudar e aprender, com respectivamente 141 e 84 professores relatando tal uso (dado não demonstrado). Além dessas ferramentas, uma pequena parte dos professores declarou utilizar a ferramenta Wiki para estudar. Entretanto, nenhum professor declarou utilizá-la para a redação coletiva de textos, o que poderia configurar um uso colaborativo da internet, o que aparentam desconhecer. Com base no prefixo utilizado no questionário (Wiki) e no uso declarado pelos professores, é bastante razoável inferir que eles tenham relacionado essa ferramenta ao uso regular que fazem da Wikipédia apenas como fonte de pesquisa e não como ferramenta de edição colaborativa. Essas ferramentas foram utilizadas de forma estritamente distributiva, mostrando que o professor realiza busca na internet para coletar informação pronta já disponível, principalmente textos, livros e artigos científicos na área de Química, configurando assim um padrão de uso da web 1.0. ${ }^{5}$

De forma geral, os professores reconhecem e utilizam a internet para fins de aprendizagem e estudo. De fato, $91 \%$ deles utilizam pelo menos uma ferramenta para essa finalidade (Figura 2), com alguns professores chegando a utilizar várias ferramentas com esse intuito. Embora a maior parte do uso da internet para estudo seja distributivo, ferramentas com características mais colaborativas também são utilizadas pelos professores. Por exemplo, $57,6 \%$ dos usos da ferramenta
Fórum foram para fins de estudo. O Fórum é utilizado pelos professores para estudar e aprender temas da área de formação e atuação, essa ferramenta está na maioria das vezes relacionada a cursos online. Outras ferramentas com potencial colaborativo, como Blog, Facebook e Ning também são utilizadas para estudar e aprender, mas por poucos professores. Em relação às redes sociais, 10 professores declararam usar Ning e apenas três o Facebook para essa finalidade.

Embora a maior parte dos professores utilize essas ferramentas para fins de socialização e para o estudo, o uso didático é muito reduzido (categoria Didático). De fato, ao levarmos em consideração os usos didáticos em relação ao total de usos declarados pelos professores (Tabela 1), identificamos que apenas $3,7 \%$ das utilizações ocorrem para essa finalidade. As ferramentas com maior número de usuários para fins de ensino são: Motores de busca, Vídeo, Download e Blog com respectivamente $21,9,8$ e 7 professores relatando tal uso (Dado não demonstrado).

Dos 186 professores, 144 (77\%) não utilizam nenhuma ferramenta da internet para ensinar (Figura 2) e, daqueles que declararam algum uso didático, $48 \%$ usam apenas pesquisa e ou download. Essas ferramentas são utilizadas para buscar recursos didáticos para a confecção de aulas e atividades, bem como obter materiais para serem usados como recursos didáticos, tais como textos, apostilas, provas, artigos científicos, livros e vídeos. Mais uma vez, fica configurado o uso preponderante da internet distributiva, não somente para obter informação pronta, mas também para repassá-la aos alunos. 


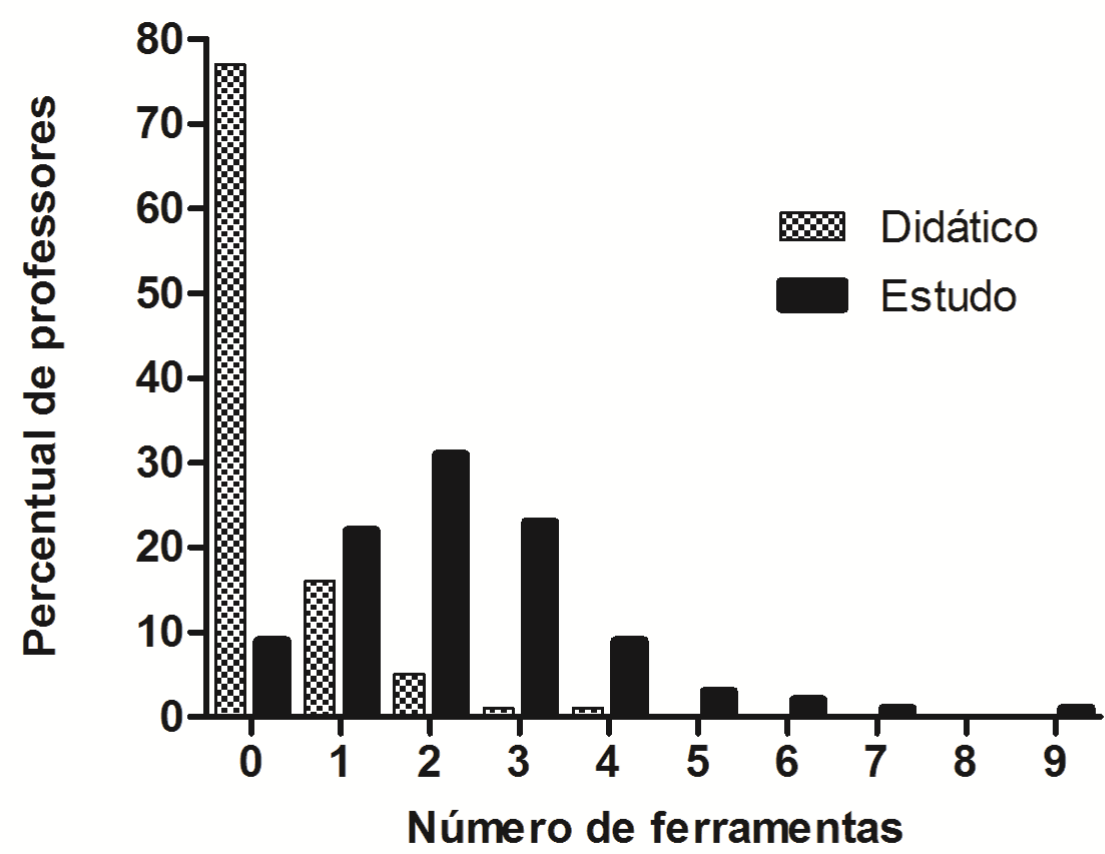

Figura 2. Número de ferramentas utilizadas pelos professores para as finalidades Estudo e Didático $(n=186)$

A busca de informação e recursos na internet merece a devida atenção, ainda mais por se tratar de professores e da relação com o conhecimento e sua disseminação no ensino. Se considerarmos a abundância de dados e recursos que podem ser recuperados usando um motor de busca na internet, torna-se claro que o uso de critérios de pesquisa apropriados, bem como a identificação de fontes confiáveis é crucial para a obtenção de informações qualificadas. $^{37}$ Segundo Santos, Firme, e Barros $^{37}$ é importante a formação de uma cultura de pesquisa pela internet complementar ao processo tradicional de pesquisa bibliográfica. ${ }^{37}$ Nesse sentido, o desenvolvimento da alfabetização informacional $^{38}$ também deve ser considerado como uma meta para programas de formação de professores, à semelhança do que tem sido recomendado para outros profissionais. $^{39}$

Dentre as ferramentas com potencial colaborativo, o Blog aparece como ferramenta com maior potencial colaborativo utilizada para fins didáticos; os professores declararam utilizá-la para disponibilizar recursos e interagir com alunos. Cabe ressaltar que apenas 4,3\% (oito) dos professores relataram esse tipo de uso. Uma percentagem muito pequena quando comparado com dados obtidos em Taiwan, onde $32 \%$ dos professores relataram o uso de blogs para o ensino. ${ }^{40}$ Outro achado importante se refere à utilização das redes sociais, já que nenhum professor declarou utilizá-las para fins didáticos. Esses dados são corroborados por estudo realizado no Brasil, com profissionais de Psicologia Médica, que mostrou que apenas $12,82 \%$ dos 64 Blogs e $1,07 \%$ das 187 comunidades do Orkut analisados foram destinadas a desenvolver atividades educacionais. ${ }^{41}$

As plataformas online nas quais as redes sociais e os blogs são construídos são ambientes virtuais repletos de ferramentas com grande potencial pedagógico, nos quais a habilidade de argumentação científica 
poderia ser explorada pelos professores juntamente com seus alunos. ${ }^{25}$ Entretanto, o potencial pedagógico dessas ferramentas tem sido subestimado, ao menos por enquanto, no ensino da Química. Nossos achados indicam que, apesar da maior parte dos professores utilizar ferramentas da internet, poucos conseguem perceber seu potencial para o ensino, e, quando o fazem, raramente exploram 0 seu potencial colaborativo.

\section{Discussão}

Os resultados encontrados nesta pesquisa são corroborados por diversos estudos encontrados na literatura, que destacam o uso limitado do potencial pedagógico das TICs e, especialmente, da internet, tanto no Brasil $^{31,32,33,41}$ como em outros países. ${ }^{16,18,19,34,42,43,44}$ Para exemplificar, um estudo realizado no Paraná identificou que professores de Química possuem limitações no que se refere ao uso das TICs, e que mesmo possuindo acesso a computadores em casa, a laboratórios de informática nas escolas e a outros equipamentos, eles ainda não utilizam as TICS nas suas aulas de Química. ${ }^{32}$ Esse resultado é corroborado por uma pesquisa realizada com professores de português e matemática da rede pública no Brasil que apontou que, mesmo tendo acesso a computadores com conexão à internet no trabalho e em casa, apenas $2 \%$ dos professores usam a tecnologia como suporte em sala de aula; e os que as usam se limitam a ensinar a alunos como utilizar o computador, sem desenvolver práticas pedagógicas inovadoras. ${ }^{31}$ Nesse mesmo sentido, numa pesquisa em Taiwan, $\mathrm{Chen}^{34}$ demonstrou que $80 \%$ de um grupo de 311 professores de Inglês utilizava a internet no ensino, mas prioritariamente por meio de motores de busca e de e-mail.

Professores de Ciências da Austrália sentem-se mais à vontade para realizar pesquisa na internet e usar o e-mail para fins pessoais do que para participar de grupos de discussão on-line. ${ }^{18}$ Segundo esse autor, mesmo em condições supostamente ideais, onde todos os alunos e professores têm acesso a computadores, o ensino por meio da internet ainda está baseado em busca de informações sobre conteúdos científicos específicos. Resultado semelhante foi encontrado em pesquisa com professores suecos recém-formados, ${ }^{42}$ em que o uso da internet na prática docente é raro. $\mathrm{O}$ reconhecimento da internet como uma ferramenta útil e benéfica foi relatado por professores canadenses, que, no entanto, a consideraram principalmente como fonte de informação. ${ }^{16}$ Segundo Gibson e Oberg ${ }^{43}$ apesar de sua atitude positiva em relação à internet, seu potencial como uma ferramenta inovadora para o ensino e aprendizagem parece ser desconhecido dos professores canadenses, que raramente relatam o uso colaborativo de ferramentas baseadas na internet. $^{43}$ É possível, portanto, que o fenômeno seja bastante generalizado.

Aparentemente $\mathrm{o}$ uso didático e $\mathrm{o}$ potencial colaborativo das ferramentas da internet permanecem distantes das salas de aula de Química. É importante ressaltarmos que existem bons repositórios de informação e recursos no campo da Química disponíveis atualmente, que os professores são usuários da internet e que grande parte deles já utiliza a internet para estudar e aprender. Dessa forma, se faz necessário levantar possibilidades para melhorar este quadro, ampliando o uso didático dos recursos virtuais, sobretudo o uso colaborativo. Relacionamos alguns fatores que podem contribuir para estreitar os laços de integração dos docentes com a internet e suas ferramentas.

\subsection{Formação inicial e continuada}

Uma importante possibilidade para que os professores passem a integrar melhor o uso da internet está em sua formação inicial, enquanto a obtenção do grau de licenciado está em curso. Por motivos que estão além do escopo desta pesquisa, é em geral na 
universidade brasileira onde justamente 0 uso de recursos inovadores encontram maior resistência e preconceito. Para remediar este problema, os cursos de formação de química, seja licenciatura ou bacharelado, poderiam incorporar o uso pedagógico das ferramentas da internet em suas discussões sobre o ensino de conteúdos científicos.

A formação continuada de professores é outra importante ação de incentivo que pode contribuir para a ampliação do uso didático da internet. Algumas ações de formação continuada ocorrem à distância por meio de plataformas virtuais. Uma das mais conhecidas é a Plataforma Paulo Freire (http://freire.mec.gov.br) e, no estado do Rio de Janeiro, os cursos de Formação de Professores da Fundação CECIERJ (www.cederj.edu.br/extensao). Embora o nível de alfabetização tecnológica do professor continue a ser um sério desafio, ${ }^{14} \mathrm{o}$ conhecimento tecnológico por si só pode ser insuficiente para uma prática profissional reflexiva e autônoma, que vá além da simples reprodução de conteúdos. ${ }^{41}$ Bransford e colaboradore $^{20}$ indicam a necessidade de buscar a melhoria do ensino, estimulando a pesquisa e a implementação de novas tecnologias de forma contextualizada ao cotidiano escolar como caminho a ser construído por pesquisadores e programas de formação e professores.

Nesse contexto, Carvalho e Gil-Pérez ${ }^{45}$ destacam a importância de "conhecer a matéria a ser ensinada", mas também a centralidade de "adquirir conhecimentos teóricos sobre a aprendizagem de ciências". Segundo os autores, é igualmente fundamental que o professor seja capaz de elaborar atividades capazes de gerar uma aprendizagem efetiva. Esse último ponto é fundamental, uma vez que muitas vezes as propostas de atividades de ensino elaboradas por profissionais especializados em um determinado campo ou por professores são mais atraentes para seus criadores do que efetivas ou atraentes para os alunos aos quais se destinam. ${ }^{46}$
A troca de experiências e a

contextualização do conhecimento compartilhado nas atividades de formação inicial ou continuada devem estar relacionadas ao dia a dia do exercício profissional, em um contínuo processo de ação-reflexão-ação. ${ }^{47,48}$ As novas tecnologias também fornecem possibilidades para esse processo, mas são os professores as pessoas chave para a adoção e ampliação de práticas educativas inovadoras. ${ }^{49}$ Dessa forma, uma proposta de melhorar a integração de tecnologia no ensino é o desenvolvimento de iniciativas didáticas a partir do modelo conceitual TPACK (Conhecimento Tecnológico Pedagógico de Conteúdo, do inglês TPACK, Technological, Pedagogical, Content, Knowledge). Ampliando o modelo proposto por Shulman, ${ }^{50}$ no qual a formação do professor deveria integrar os conhecimentos pedagógicos com o aprofundamento nos conhecimentos conceituais, vários autores $^{51,52,53}$ têm construído um modelo de formação da base conceitual do professor apoiado neste tripé composto dos eixos pedagógico e conceitual, mas também do tecnológico.

\subsection{Políticas institucionais}

Na educação básica, em geral, a oferta de recursos tecnológicos para os professores ainda é deficitária. Ainda que pese a doação ou facilidades especiais para a aquisição de tablets ou laptops, o professor do ensino público frequentemente não possui acesso à internet em velocidade adequada ou salas de aulas em boas condições de funcionamento ${ }^{14}$. Existe, portanto, uma premência na articulação entre as políticas em diferentes níveis, a fim de promover condições técnicas e estruturais para a utilização das ferramentas da internet na formação docente. Deve estar também aí embutida a necessidade de criar oportunidades para a troca de conhecimento e experiência docente entre os professores e destes com seus alunos, no ensino de Química ou nas demais áreas. Estas 
oportunidades podem ser promovidas com a criação de blogs ou redes sociais especificas para cada programa, entre outras ferramentas da Web 2.0.

Recentemente, a plataforma Lattes (lattes.cnpq.br), o principal banco de publicação de currículos acadêmicos em nosso país, passou a incorporar como produção o registro do uso de redes sociais e blogs. Apesar de ainda não constar como um indicador de mérito acadêmico ou progressão profissional trata-se de uma abertura que pode promover maior interesse no uso dessas tecnologias.

\subsection{0 fator sociocultural}

Um dos motivos para a não utilização de redes sociais para fins educacionais reside na possibilidade de criar conflito com os estudantes, já que o aluno utiliza esse espaço para compartilhar sua vida pessoal e social com amigos e parentes. ${ }^{54}$ Segundo Jones, Blackey, Fitzgibbon e $\mathrm{Chew}^{54}$ os alunos recebem com estranhamento a utilização didática deste ambiente. Como os professores usualmente não estão atualizados, eles não sabem como integrar e fazer uso conveniente das redes sociais no ensino e aprendizagem. Há também poucos softwares disponíveis que possibilitem o diálogo de uma forma mais efetiva com os alunos. No âmbito da química, os recursos frequentemente se limitam a vídeos ou aplicativos ainda pouco atrativos para os nativos da era digital, com baixíssimas possibilidades de interação e mecanismos de estímulo-recompensa. O financiamento e a amplitude de interesse acadêmico ainda são modestos em relação ao nível de complexidade necessário para a criação de novos aplicativos.

Deve-se também ponderar a disponibilidade de tempo e motivação suficientes para os professores praticarem o uso das novas tecnologias, a fim de estarem preparados para os desafios de sua atividade na sala de aula. ${ }^{55}$ Nesse sentido, outros fatores precisam ser considerados, como a distribuição da carga horária, a saturação do currículo escolar em paralelo à falta de preparo do aluno e do professor, além do inadequado reconhecimento salarial. Outra face da mesma moeda é que o professor se depara hoje com uma realidade social muito mais complexa, tangenciado principalmente pela banalização das relações, onde o seu próprio papel é frequentemente confrontado. A reflexão acerca do uso de novas formas de aprendizado torna-se frequentemente um esforço inócuo, na medida em que condições básicas para o qualificado exercício profissional são negligenciadas.

\section{Conclusões}

Os professores analisados no presente estudo são usuários frequentes da internet, utilizando principalmente o e-mail para fins de comunicação e os motores de busca associados ao Download para a obtenção de informações que são distribuídas na rede. De forma geral, as ferramentas da internet são pouco utilizadas para fins didáticos no exercício do magistério da química. De fato, nenhum professor declarou utilizar redes sociais para essa finalidade, embora a maior parte deles faça uso dessas ferramentas para fins sociais. Os professores parecem desconhecer o potencial colaborativo de ferramentas como Fórum, Blog e redes sociais.

Apesar de estarmos inseridos na sociedade da informação e do conhecimento, na qual o uso das tecnologias de informação, comunicação e compartilhamento, especialmente a internet, está bastante difundido, principalmente entre os jovens e adolescentes, os professores fazem um uso limitado das mesmas na sua prática docente. Por exemplo, a ausência de ferramentas colaborativas, como as preconizadas na web 2.0, limita suas possibilidades de estimular, ao menos pelas vias tecnológicas mais atuais, a construção colaborativa, proximidade e 
autossuficiência no aprendizado do aluno. Esses frequentemente usufruem das tecnologias modernas com mais desenvoltura do que os seus docentes.

A despeito do esforço e do investimento na educação focada em novas tecnologias, os modelos apresentados ainda não têm sido suficientemente compensados, há que se investigar mais sobre as habilidades ou interesses dos professores em seu uso no ensino e na aprendizagem. Ainda há também muito que aprender e praticar para tornar o uso das ferramentas de internet mais convincente e ou efetivo em sala de aula e nos fatores que contribuem para esta integração.

\section{Anexo 1.}

Questionário de uso da internet (QUI)

1- Com qual frequência você utiliza a internet? Raramente - 1 dia/semana - 2 dias/semana - 3 dias/semana - 4 dias/semana - 5 dias/semana - 6 dias/semana - Todos os dias

2- Você faz pesquisa na internet? Sim ou Não. Para quê?

3- Você utiliza e-mail? Sim ou Não. Para quê?

4- Você utiliza chat? Sim ou Não. Para quê?

5- Você utiliza Twitter? Sim ou Não. Para quê?

6- Você utiliza Skype? Sim ou Não. Para quê?

7- Você utiliza download? Sim ou Não. Para quê?

8- Você utiliza upload? Sim ou Não. Para quê?

9- Você utiliza fotos? Sim ou Não. Para quê?

10- Você utiliza vídeos? Sim ou Não. Para quê?

11- Você utiliza Wiki? Sim ou Não. Para quê?

12- Você utiliza blog? Sim ou Não. Para quê?

13- Você utiliza fórum? Sim ou Não. Para quê?
14- Você utiliza Orkut? Sim ou Não. Para quê?

15- Você utiliza Facebook? Sim ou Não. Para quê?

16- Você utiliza Myspace? Sim ou Não. Para quê?

17- Você utiliza Ning? Sim ou Não. Para quê?

18- Você utiliza Second Life? Sim ou Não. Para quê?

\section{Referências Bibliográficas}

1 Lévy, P.; Cyberculture, University of Minnesota Press: Minneapolis, 2001.

${ }^{2}$ Castells, M.; Cardoso, G; The network society: from knowledge to policy, Johns Hopkins Center for Transatlantic Relations: Washington, 2005.

${ }^{3}$ Goodyear, P.; Banks, S.; Hodgson, V.; Mcconnell, D.; Advances in research on networked learning, Kluwer Academic Publishers: Dordrecht, Netherlands, 2004.

${ }^{4}$ Martin, S.; Diaz, G.; Sancristobal, E.; Gil, R.; Castro, M.; Peire, J. New technology trends in education: Seven years of forecasts and convergence. Computers \& Education 2011, 3, 1893. [CrossRef]

${ }^{5}$ Oreilly, T. What is Web 2.0: Design patterns and business models for the next generation of software. Communications \& Strategies 2007, 65, 17. [Link]

${ }^{6}$ Becta. What the research says about using ICT in science. Report to the BECTA ICT Research network, 2003. [Link]

${ }^{7}$ American Association for the Advancement of Science. Benchmarks for science literacy: Project 2061. Oxford: Oxford University Press, 1993. [Link]

${ }^{8}$ Unesco. Hacia las sociedades del conocimiento. Editorial UNESCO. Paris, France, 2005. [Link]

${ }^{9}$ Unesco. ICT competency standards for teachers. United Kingdom, 2008. [Link]

${ }^{10}$ Unesco. Unesco ICT competency framework for teachers. Paris, France, 2011. [Link]

${ }^{11}$ CNE. Resolução CNE/CP no 1 , de 18 de fevereiro de 2002. Institui Diretrizes

Rev. Virtual Quim. |Vol 7| |No. 3| |864-879| 
Curriculares Nacionais para a Formação de Professores da Educação Básica, em nível superior, curso de licenciatura, de graduação plena. Insitui diretrizes Curriculares Nacionais. Brasília, DF, 2002. [Link]

${ }^{12}$ Conae. Construindo o Sistema Nacional Articulado de Educação: o Plano Nacional de Educação, diretrizes e estratégias; documento Final. Brasília: INEP. Brasília, DF, 2010. [Link]

${ }^{13}$ Fnde. Resolução/FNDE/CD/no 17 de 10 de junho de 2010. Brasília, DF, 2010. [Link]

${ }^{14}$ Fidalgo-Neto, A. A.; Tornaghi, A. J. C.; Meirelles, R. M. S.; Berçot, F. F.; Xavier, L. L.; Castro, M. F. A.; Alves, L. A. The use of computers in Brazilian primary and secondary schools. Computers \& Education 2009, 3, 677. [CrossRef]

${ }^{15}$ Law, N.; Lee, M. W.; Chan, A. Policy impacts on pedagogical practice and ICT use: an exploration of the results from SITES 2006. Journal of Computer Assisted Learning 2010, 6, 465. [CrossRef]

${ }^{16}$ Martinovic, D.; Zhang, Z. Situating ICT in the teacher education program: Overcoming challenges, fulfilling expectations. Teaching and Teacher Education 2012, 3, 461. [CrossRef]

${ }^{17}$ Plomp, T.; Pelgrum, W. J.; Law, N. SITES2006-International comparative survey of pedagogical practices and ICT in education. Education and Information Technologies 2007, 2, 83. [CrossRef]

${ }^{18}$ Dawson, V. Use of Information Communication Technology by Early Career Science Teachers in Western Australia. International Journal of Science Education 2008, 2, 203. [CrossRef]

${ }^{19}$ Hinostroza, J. E.; Labbé, C.; Brun, M.; Matamala, C. Teaching and learning activities in Chilean classrooms: Is ICT making a difference? Computers \& Education 2011, 1, 1358. [CrossRef]

${ }^{20}$ Bransford, J. D.; Brow, A. L.; Cocking, R. R.; Como as pessoas aprendem: cérebro, mente, experiência e escola, Senac: São Paulo, 2007.

${ }^{21}$ Alves, L.; Nativos Digitais: Games, Comunidades e Aprendizagens; Moraes, U. C. de. Ed.; Tecnologia Educacional e Aprendizagem: o uso dos recursos digitais. Livro Pronto: São Paulo, 2007.
22 Prensky, M. Digital Natives, Digital Immigrants. On the Horizon 2001, 5, 1. [CrossRef]

${ }^{23}$ Osborne, J.; Hennessy, S.; Literature Review in Science Education and the Role of ICT: Promise, Problems and Future Directions. Bristol: United Kingdom, 2003. [Link]

${ }^{24}$ Gray, L.; Thomas, N.; Lewis, L.; Teachers' Use of Educational Technology in U.S. Public Schools: 2009. Washington, D.C., 2010. [Link]

${ }^{25}$ Lee, S. W.-Y.; Tsai, C.-C.; Wu, Y.-T.; Tsai, M.J.; Liu, T.-C.; Hwang, F.-K.; Lai, C.-H.; Liang, J.C.; Wu, H.-C.; Chang, C.-Y. Internet-based Science Learning: A review of journal publications. International Journal of Science Education 2011, 14, 1893. [CrossRef]

${ }^{26}$ Martinho, T.; Pombo, L. Potencialidades das TIC no ensino das Ciências Naturais-um estudo de caso. Revista Electrónica de Enseñanza de Las Ciencias 2009, 2, 527. [Link] ${ }^{27}$ Marson, G.; Galembeck, E.; Andrade, J. de. Química nova interativa-QNInt-o portal do conhecimento da SBQ: conectando ciência e educação. Química Nova 2013, 3, 484. [CrossRef]

${ }^{28}$ Rolando, L. G. R.; Salvador, D. F.; Luz, M. R. $M$. P. The use of internet tools for teaching and learning by in-service biology teachers: A survey in Brazil. Teaching and Teacher Education 2013, 34, 46. [CrossRef]

${ }^{29}$ Fraenkel, J. R.; Wallen, N.; How to design and evaluate research in education, McGrawHill: New York, 2003.

${ }^{30}$ Ibope Nielsen Online. IBOPE NetRatings Dados de 2011. 2012. [Link]

${ }^{31}$ Cetic. Pesquisa sobre o uso das TIC nas escolas brasileiras: TIC Educação 2012. São Paulo, 2013. [Link]

${ }^{32}$ Aires, J. A.; Lambach, M. Contextualização do ensino de química pela problematização e alfabetização científica e tecnológica: uma possibilidade para a formação continuada de professores. Revista Brasileira de Pesquisa em Educação em Ciências 2010, 1, 1. [Link] ${ }^{33}$ Costa, V. V.; Medeiros, M. A. Em Encontro nacional de pesquisa em educação em ciências, Florianópolis, Brasil 2009.

${ }^{34}$ Chen, Y.-L. A mixed-method study of EFL teachers' Internet use in language instruction. Teaching and Teacher Education 2008, 4, 1015. [CrossRef] 
${ }^{35}$ Comscore. The Rise of Social Networking in Latin America: How Social Media is Shaping Latin America's Digital Landscape, 2011. [Link]

${ }^{36}$ Comscore. Facebook Continues its Global Dominance, Claiming the Lead in Brazil, 2012. [Link]

${ }^{37}$ Santos, A. R. dos; Firme, C. L.; Barros, J. C. A Internet como fonte de informação bibliográfica em Química. Química Nova 2008, 2, 445. [CrossRef]

${ }^{38}$ American Library Association. Information Literacy Competency Standards for Higher Education. American Library Association: Chicago, 2000. [Link]

${ }^{39}$ Brettle, A. Evaluating information skills training in health libraries: a systematic review. Health Information and Libraries Journal 2007, 1, 18. [CrossRef]

${ }^{40}$ Lai, H.-M.; Chen, C.-P. Factors influencing secondary school teachers' adoption of teaching blogs. Computers \& Education 2011, 4, 948. [CrossRef]

${ }^{41}$ Maia, F.; Struchiner, M. Utilização dos weblogs e de comunidades do orkut como ferramentas pedagógicas em cursos da área da saúde. Interface-Comunicação, Saúde, Educação 2010, 35, 905. [CrossRef]

${ }^{42}$ Andersson, S. B. Newly qualified teachers' learning related to their use of information and communication technology: a Swedish perspective. British Journal of Educational Technology 2006, 5, 665. [CrossRef]

${ }^{43}$ Gibson, S.; Oberg, D. Visions and realities of Internet use in schools: Canadian perspectives. British Journal of Educational Technology 2004, 5, 569. [CrossRef]

${ }^{44}$ Lee, M.-H.; Tsai, C.-C. Exploring teachers' perceived self-efficacy and technological pedagogical content knowledge with respect to educational use of the World Wide Web. Instructional Science 2008, 1, 1. [CrossRef] ${ }^{45}$ Carvalho, A. de; Gil-Pérez, D.; Formação de professores de ciências: tendências e inovações. 10a ed., Editora Cortez: São Paulo,
2011.

${ }^{46}$ Villani, A.; Almeida Pacca, J. L.; Freitas, D. Science Teacher Education in Brazil: 19502000. Science \& Education 2009, 1, 125. [CrossRef]

${ }^{47}$ Bonzanini, T. K.; Bastos, F.; Formação continuada de professores de ciências: algumas reflexões. Em Encontro nacional de pesquisa em educação em ciências, Florianópolis, Brasil 2009.

${ }^{48}$ Schon, D. A.; The Reflective Practitioner: How Professionals Think In Action. Basic Books: New York, 1983.

49 Pettenati, M.; Giuli, D.; Khaled, O. Information technology and staff development: Issues and problems related to new skills and competence acquisition. Journal of Technology and Teacher Education 2001, 2, 1. [Link]

${ }^{50}$ Shulman, L. S. Knowledge and Teaching: Foundations of New Reform. Harvard Educational Review 1987, 1, 1. [Link]

${ }^{51}$ Angeli, C.; Valanides, N. Epistemological and methodological issues for the conceptualization, development, and assessment of ICT-TPCK: Advances in technological pedagogical content knowledge (TPCK). Computers \& Education 2009, 1, 154. [CrossRef]

${ }^{52}$ Mishra, P.; Koehler, M. J. Technological Pedagogical Content Knowledge: A Framework for Teacher Knowledge. Teachers College Record 2006, 6, 1017. [Link]

${ }^{53}$ Koehler, M. J.; Mishra, P.; Yahya, K. Tracing the development of teacher knowledge in a design seminar: Integrating content, pedagogy and technology. Computers \& Education 2007, 3, 740. [CrossRef]

54 Jones, N.; Blackey, H.; Fitzgibbon, K.; Chew, E. Get out of MySpace! Computers \& Education 2010, 3, 776. [CrossRef]

${ }^{55}$ Zhang, Z.; Martinovic, D. ICT in teacher education: Examining needs, expectations and attitudes. The Canadian Journal of Learning and Technology 2008, 2, 149. [Link] 